\title{
Extended structures based on hydrogen bonding and $\pi-\pi$ interactions: synthesis and characterization of two zinc complexes: $\left[\mathrm{Zn}(\right.$ dap $\left.) \mathrm{Cl}_{2}\right]$ and $\left[\mathrm{Zn}(\text { dap })_{2} \mathrm{Cl}_{2}\right]$
}

\author{
Carmen de Cires-Mejias ${ }^{a, b}$, Stefania Tanase ${ }^{a}$, Jan Reedijk ${ }^{\text {a,* }}$, \\ Francisco González-Vílchez ${ }^{\mathrm{b}}$, Rosario Vilaplana ${ }^{\mathrm{b}}$, Allison M. Mills ${ }^{\mathrm{c}}$, \\ Huub Kooijman ${ }^{\mathrm{c}}$, Anthony L. Spek ${ }^{\mathrm{c}}$ \\ ${ }^{a}$ Gorlaeus Laboratories, Leiden Institute of Chemistry, Leiden University, P.O. Box 9502, 2300 RA Leiden, The Netherlands \\ ${ }^{b}$ Bioinorganic Chemistry Laboratory, Inorganic Chemistry Department, Chemistry Faculty, University of Seville, \\ Campus de Reina Mercedes Apdo 553, 41071 Seville, Spain \\ ${ }^{\mathrm{c}}$ Bijvoet Center for Biomolecular Research, Utrecht University, Padualaan 8, 3584 CH Utrecht, The Netherlands
}

Received 29 October 2003; accepted 29 November 2003

\begin{abstract}
Two new $\mathrm{Zn}(\mathrm{II})$ complexes, $\left[\mathrm{Zn}(\mathrm{dap}) \mathrm{Cl}_{2}\right]$ (1) and $\left[\mathrm{Zn}(\mathrm{dap})_{2} \mathrm{Cl}_{2}\right]$ (2) (dap stands for 2,3-diaminopyridine), were prepared and spectroscopically and crystallographically characterized. In both compounds, the zinc(II) atom has a pseudo-tetrahedral $\mathrm{ZnN}_{2} \mathrm{Cl}_{2}$ coordination environment. Compound $\mathbf{1}$ adopts a three-dimensional structure built up from $\left[\mathrm{Zn}(\mathrm{dap}) \mathrm{Cl}_{2}\right]_{n}$ zig-zag chains, which are linked by $\mathrm{N}-\mathrm{H} \cdots \mathrm{Cl}$ hydrogen bonds. In compound $\mathbf{2}$ the dap is monodentate coordinating via the pyridine nitrogen; the mononuclear tetrahedral $\left[\mathrm{Zn}(\text { dap })_{2} \mathrm{Cl}_{2}\right]$ units are linked into two-dimensional sheets through extensive $\mathrm{N}-\mathrm{H} \cdots \mathrm{Cl}$ hydrogen bonding. Inter-sheet $\pi-\pi$ interactions connect them into a three-dimensional network.
\end{abstract}

(C) 2003 Elsevier B.V. All rights reserved.

Keywords: Zinc; Aminopyridine; Hydrogen bonds

\section{Introduction}

In the last years, a pronounced interest has been focused on the engineering of supramolecular architectures organized, not only by covalent and coordinative bonds, but also by supramolecular interactions, such as hydrogen bonds and $\pi-\pi$ interactions [1-5]. In particular, the crystal-engineering of noncentrosymmetric infinite coordination polymers has proven to be a very useful tool for the synthesis of nonlinear optical materials [6,7]. Non-centrosymmetric coordination networks can be rationally designed by combining well-defined metal coordination geometries with carefully chosen ri-

\footnotetext{
${ }^{*}$ Corresponding author. Tel.: +31-71-5274450; fax: +31-71-5274671.

E-mail address: reedijk@chem.leidenuniv.nl (J. Reedijk).
}

gid bridging ligands. As part of this research a variety of zinc-pyridine coordination compounds have been explored [8-11]. The pseudo-tetrahedral metal ion $\mathrm{Zn}(\mathrm{II})$ $\left(\mathrm{d}^{10}\right)$ has been used as connecting point in order to avoid unwanted optical losses from $\mathrm{d}-\mathrm{d}$ transitions in the visible region. The unsymmetrical pyridine-based bridging ligands have been chosen in order to minimize potential packing complexity and to introduce electronic asymmetry, factors necessary for nonlinear optical effects.

In the present paper, we report the synthesis and structural characterization of two new zinc coordination compounds, $\left[\mathrm{Zn}(\mathrm{dap}) \mathrm{Cl}_{2}\right]$ (1) and $\left[\mathrm{Zn}(\mathrm{dap})_{2} \mathrm{Cl}_{2}\right]$ (2) (dap stands for 2,3-diaminopyridine), which have a tetrahedral molecular configuration. Although the organic ligand is a relatively simple and commercially available one, no coordination compounds of this ligand have yet been published, to the best of our knowledge. 


\section{Experimental}

\subsection{Synthesis}

2,3-Diaminopyridine and $\mathrm{ZnCl}_{2}$ anhydrous were purchased from Aldrich and Merck, respectively, and used as received. All other chemicals were of reagent grade quality and were used without further purification.

\subsection{1. [Zn(dap) $\left.\mathrm{Cl}_{2}\right]$ (1)}

Dark orange crystals of the compound were obtained by slow diffusion of diethyl ether into a methanolic solution containing zinc chloride $(68 \mathrm{mg}, 0.5 \mathrm{mmol})$ and dap (55 mg, $0.5 \mathrm{mmol}$ ). Crystals were filtered, washed with diethyl ether and dried in vacuum. Yield: 54(\%). Anal. Calc. for $\mathrm{C}_{5} \mathrm{H}_{7} \mathrm{Cl}_{2} \mathrm{ZnN}_{3}: \mathrm{C}, 24.5 ; \mathrm{H}, 2.9 ; \mathrm{N}, 17.1$. Found: C, $24.8 ; \mathrm{H}, 2.9 ; \mathrm{N}, 17.0 \%$. IR $\left(v_{\max } / \mathrm{cm}^{-1}\right): 3426 \mathrm{~s}$, $3335 \mathrm{~s}, 3235 \mathrm{~s}, 3142 \mathrm{~s}, 1653 \mathrm{~s}, 1624 \mathrm{~s}, 1574 \mathrm{~m}, 1486 \mathrm{~s}, 1458 \mathrm{~s}$, $1253 \mathrm{~m}, 1050 \mathrm{~s}, 779 \mathrm{~m}, 749 \mathrm{~s}, 645 \mathrm{~m}, 611 \mathrm{~m}, 482 \mathrm{~m}, 456 \mathrm{~s}$, $374 \mathrm{~m}, 351 \mathrm{~s} \mathrm{~cm}^{-1}$. UV-Vis $\left(\lambda_{\max } / \mathrm{nm}\right): 372,331,260 .{ }^{1} \mathrm{H}$ NMR (dmso-d 6 , $\delta / \mathrm{ppm}): 7.25$ (H, dd), 6.70 (H, dd), 6.40 $(\mathrm{H}, \mathrm{q}), 5.61(2 \mathrm{H}, \mathrm{s}), 4.78(2 \mathrm{H}, \mathrm{s})$.

\subsection{2. $\left[\mathrm{Zn}(\mathrm{dap})_{2} \mathrm{Cl}_{2}\right]$ (2)}

Dark orange crystals of the compound were obtained by slow evaporation of a methanolic solution containing zinc chloride $(68 \mathrm{mg}, 0.5 \mathrm{mmol})$ and dap $(110 \mathrm{mg}, 1.0$ mmol). Crystals were filtered, washed with diethyl ether and dried in vacuum. Yield: $66(\%)$. Anal. Calc. for $\mathrm{C}_{10} \mathrm{H}_{14} \mathrm{Cl}_{2} \mathrm{ZnN}_{6}$ : C, 33.9; H, 3.98; N, 23.70. Found: $\mathrm{C}$, 33.95; H, 3.64; N, 23.71\%. IR $\left(v_{\max } / \mathrm{cm}^{-1}\right): 3371 \mathrm{~s}, 3322 \mathrm{~s}$, 3196s, 3199s, 1647s, 1625s, 1573m, 1479s, 1455s, 1236m, $780 \mathrm{~m}, 745 \mathrm{~s}, 668 \mathrm{~m}, 612 \mathrm{~m}, 479 \mathrm{~s}, 345 \mathrm{~s} \mathrm{~cm}^{-1}$. UV-Vis ( $\left.\lambda_{\max } / \mathrm{nm}\right): 380,344,268 .{ }^{1} \mathrm{H}$ NMR $\left(\right.$ dmso-d $\left._{6}, \delta / \mathrm{ppm}\right)$ : $7.24(\mathrm{H}, \mathrm{dd}), 6.68(\mathrm{H}, \mathrm{dd}), 6.35(\mathrm{H}, \mathrm{q}), 5.38(2 \mathrm{H}, \mathrm{s}), 4.65$ $(2 \mathrm{H}, \mathrm{s})$.

\subsection{Physical measurements}

$\mathrm{C}, \mathrm{H}$ and $\mathrm{N}$ analyses were performed with a PerkinElmer 2400 series II analyzer. Infrared spectra (4000$300 \mathrm{~cm}^{-1}$, resp. $4 \mathrm{~cm}^{-1}$ ) were recorded on a Perkin-Elmer Paragon 1000 FTIR spectrometer equipped with a Golden Gate ATR device, using the reflectance technique. Diffuse reflectance spectra were obtained on a Perkin-Elmer Lambda 900 spectrophotometer, with $\mathrm{MgO}$ as a reference. ${ }^{1} \mathrm{H}$ NMR spectra were recorded on a Bruker DPX-300 spectrometer operating at a frequency of $300 \mathrm{MHz}$.

\subsection{X-ray crystallographic analysis and data collection}

Intensity data for a single crystals of compounds $\mathbf{1}$ and 2 were collected using $\mathrm{Mo}-\mathrm{K} \alpha$ radiation $(\lambda=0.71073 \AA)$ on a Nonius KappaCCD diffractometer equipped with a rotating anode. Empirical absorption correction was applied to the data sets of both compounds.

For compound 1 a correction based on multiple measurement of symmetry-related reflections was applied (PLATON/MULABS [12], 0.549-0.900 transmission range). Compound 2 was corrected with an $\Delta \mathrm{F}$ based algorithm (PLATON/DELABS [12], 0.555-0.883 transmission range). The structures were solved by automated Patterson methods using DIR DIF99 [13] (compound 2) or by direct methods using sheLXs97 [14] (compound 1). Both structures were refined on $F^{2}$ by least-squares procedures using SHELXL97 [15]. All nonhydrogen atoms were refined with anisotropic displacement parameters. The amine hydrogen atoms were positively identified in a difference Fourier map, and their positions were refined with the restraint that for compound 2 the geometries of the $\mathrm{NH}_{2}$ substituents at the same position on the pyridine rings be similar. All other hydrogen atoms were constrained to idealized geometries and allowed to ride on their carrier atoms. All hydrogen atoms were refined with an isotropic displacement parameter related to the equivalent displacement parameter of their carrier atoms. Compound 1 proved to be a pseudo-merohedral twin with a twofold rotation around the $c$-axis as the twin operation. The twin fraction refined to a value of $0.0320(12)$. Structure validation and molecular graphics preparation were performed with the PLATON package [12].

\section{Results and discussions}

\subsection{Synthesis and spectroscopic properties}

The reaction of $\mathrm{ZnCl}_{2}$ with dap in the ratios 1:1 and 1:2 afforded two $\mathrm{Zn}(\mathrm{II})$ complexes (1 and $\mathbf{2}$ ), which were spectroscopically characterized. Complexes $\mathbf{1}$ and $\mathbf{2}$ are poorly soluble in most solvents, except DMSO and water.

In the IR spectrum of free solid dap, the characteristic bands of the hydrogen bonded $\mathrm{PyNH}_{2}$ are present at $3329 \mathrm{~cm}^{-1}\left(v_{\text {sym }}\left(\mathrm{NH}_{2}\right)\right), 3175 \mathrm{~cm}^{-1}\left(v_{\text {asym }}\left(\mathrm{NH}_{2}\right)\right)$ and $1630 \mathrm{~cm}^{-1}\left(\delta \mathrm{NH}_{2}\right)$. It has been reported that coordination of the amino group significantly shifts $v\left(\mathrm{NH}_{2}\right)$ and $\delta\left(\mathrm{NH}_{2}\right)$ [16]. Indeed, in the infrared spectrum of $\mathbf{1}$, bands corresponding to $v\left(\mathrm{NH}_{2}\right)\left(3426\right.$ and $\left.3235 \mathrm{~cm}^{-1}\right)$ and $\delta\left(\mathrm{NH}_{2}\right)\left(1653 \mathrm{~cm}^{-1}\right)$ shifted to higher frequencies are observed. However, since free amino groups are still present, other bands that are not significantly shifted are also observed $\left(v_{\text {as }}\left(\mathrm{NH}_{2}\right)\right.$ at $3335 \mathrm{~cm}^{-1}, v_{\mathrm{s}}\left(\mathrm{NH}_{2}\right)$ at 3142 $\mathrm{cm}^{-1}$ and $\delta\left(\mathrm{NH}_{2}\right)$ at $\left.1624 \mathrm{~cm}^{-1}\right)$. The band corresponding to $v(\mathrm{C}-\mathrm{N})$, which is located in the infrared spectrum of the free ligand at $1249 \mathrm{~cm}^{-1}$ is shifted to higher frequency $\left(1253 \mathrm{~cm}^{-1}\right)$ in compound $\mathbf{1}$, as result of the coordination. In the infrared spectrum of $\mathbf{2}$, the 
bands corresponding to $v\left(\mathrm{NH}_{2}\right)$ and $\delta\left(\mathrm{NH}_{2}\right)$ occur at frequencies slightly higher than observed for the free ligand, while the band corresponding to $v(\mathrm{C}-\mathrm{N})$ is shifted to lower frequency $\left(1236 \mathrm{~cm}^{-1}\right)$. In the IR spectra of both compounds, strong, broad bands near $1630 \mathrm{~cm}^{-1}$ corresponding to $\delta\left(\mathrm{NH}_{2}\right)$ obscure the $v(\mathrm{C}=\mathrm{N})$ vibrations.

The ${ }^{1} \mathrm{H}$ NMR spectra of DMSO-d ${ }^{6}$ solutions of $\mathbf{1}$ and 2 were measured in order to test the stability of both compounds in solution. In the ${ }^{1} \mathrm{H}$ NMR spectrum of $\mathbf{1}$, the signals of the amino groups are shifted to lower field compared with the free ligand in DMSO, in agreement with coordination of the amino group. For the compound 2, the ${ }^{1} \mathrm{H}$ NMR spectrum contains all of the characteristic ligand peaks shifted to slightly higher ppm values with respect to the free ligand. Due to the symmetry of the complex in solution, only one set of ligand signals appears between 4.6 and $7.3 \mathrm{ppm}$.

\subsection{Description of crystal structures}

The structures of complexes $\mathbf{1}$ and $\mathbf{2}$ were determined by X-ray crystallography. Crystallographic data are presented in Table 1 and selected bond lengths and angles are listed in Table 2.

A Pluton projection of the zig-zag $\left[\mathrm{Zn}(\mathrm{dap}) \mathrm{Cl}_{2}\right]_{n}$ chain of $\mathbf{1}$ is depicted in Fig. 1. Each zinc center has a pseudo-tetrahedral geometry, consisting of two chloride ions and two different dap ligands, one coordinated through the nitrogen atom of the pyridine ring, as is usually observed in combination with a coordinating chloride anion [17], and the second through an amino

Table 1

Crystal and structure refinement data for $\left[\mathrm{Zn}(\mathrm{dap}) \mathrm{Cl}_{2}\right]$ and $\left[\mathrm{Zn}(\mathrm{dap})_{2} \mathrm{Cl}_{2}\right]$

\begin{tabular}{lll}
\hline & {$\left[\mathrm{Zn}(\mathrm{dap}) \mathrm{Cl}_{2}\right]$} & {$\left[\mathrm{Zn}(\mathrm{dap})_{2} \mathrm{Cl}_{2}\right]$} \\
\hline Chemical formula & $\mathrm{C}_{5} \mathrm{H}_{7} \mathrm{Cl}_{2} \mathrm{~N}_{3} \mathrm{Zn}$ & $\mathrm{C}_{10} \mathrm{H}_{14} \mathrm{Cl}_{2} \mathrm{~N}_{6} \mathrm{Zn}$ \\
Molecular weight & 245.43 & 354.54 \\
Crystal system & monoclinic & monoclinic \\
Space group & $P 2_{1} / c$ & $P 2_{1} / c$ \\
$a(\AA)$ & $9.2853(10)$ & $8.7657(4)$ \\
$B(\AA)$ & $6.388(2)$ & $12.6003(6)$ \\
$c(\AA)$ & $16.324(3)$ & $13.7483(7)$ \\
$\beta\left({ }^{\circ}\right)$ & $121.595(10)$ & $113.831(3)$ \\
$V\left(\AA^{3}\right)$ & $824.7(3)$ & $1389.04(12)$ \\
$Z$ & 4 & 4 \\
$\left.D_{\text {calc }}(\mathrm{Mg} \mathrm{m})^{-3}\right)$ & 1.977 & 1.695 \\
$\mu(\mathrm{Mo} \mathrm{K} \alpha)\left(\mathrm{mm}{ }^{-1}\right)$ & 3.558 & 2.147 \\
Crystal size $\left(\mathrm{mm}^{\prime}\right)$ & $0.03 \times 0.21 \times 0.33$ & $0.24 \times 0.18 \times 0.06$ \\
$T(\mathrm{~K})$ & 150 & 150 \\
Data collected & 22263 & 10550 \\
Unique data & 1890 & 2716 \\
$R_{\text {int }}$ & 0.058 & 0.052 \\
$R(F)[I>2 \sigma(I)]$ & 0.030 & 0.030 \\
& {$[1741$ reflections $]$} & {$[2047$ reflections $]$} \\
$R_{w}\left(F^{2}\right)$ & 0.077 & 0.071 \\
$S$ & 1.20 & 1.03 \\
$\Delta \rho_{\text {min }}, \Delta \rho_{\text {max }}\left(\mathrm{e} \AA^{-3}\right)$ & $-0.51,0.82$ & $-0.34,0.45$ \\
\hline & &
\end{tabular}

Table 2

Selected bond distances $(\AA)$ and angles $\left({ }^{\circ}\right)$ for compounds $\mathbf{1}$ and $\mathbf{2}$

\begin{tabular}{|c|c|c|c|}
\hline \multicolumn{2}{|l|}{$\left[\mathrm{Zn}(\mathrm{dap}) \mathrm{Cl}_{2}\right]$} & \multicolumn{2}{|l|}{$\left[\mathrm{Zn}(\mathrm{dap})_{2} \mathrm{Cl}_{2}\right]$} \\
\hline \multicolumn{4}{|l|}{ Bond distances } \\
\hline Zn1-C11 & $2.2476(12)$ & $\mathrm{Zn} 1-\mathrm{Cl} 1$ & $2.2479(8)$ \\
\hline $\mathrm{Zn} 1-\mathrm{Cl} 2$ & $2.2264(12)$ & $\mathrm{Zn} 1-\mathrm{Cl} 2$ & $2.2475(7)$ \\
\hline Zn1-N11 & $2.046(3)$ & $\mathrm{Zn1-N11}$ & $2.038(3)$ \\
\hline Zn1-N18 & $2.104(3)$ & $\mathrm{Zn} 1-\mathrm{N} 21$ & $2.050(2)$ \\
\hline \multicolumn{4}{|l|}{ Bond angles } \\
\hline $\mathrm{Cl} 1-\mathrm{Zn} 1-\mathrm{Cl} 2$ & $112.78(4)$ & $\mathrm{Cl} 1-\mathrm{Zn} 1-\mathrm{Cl} 2$ & $111.67(3)$ \\
\hline $\mathrm{Cl1}-\mathrm{Zn} 1-\mathrm{N} 11$ & $111.70(8)$ & Cl1-Zn1-N11 & $111.61(7)$ \\
\hline Cl1-Zn1-N18 & $105.70(9)$ & $\mathrm{Cl1}-\mathrm{Zn} 1-\mathrm{N} 21$ & $112.41(7)$ \\
\hline $\mathrm{Cl} 2-\mathrm{Zn} 1-\mathrm{N} 11$ & $111.45(8)$ & $\mathrm{Cl} 2-\mathrm{Zn} 1-\mathrm{N} 11$ & $109.27(6)$ \\
\hline $\mathrm{C} 12-\mathrm{Zn} 1-\mathrm{N} 18$ & $112.20(9)$ & $\mathrm{Cl} 2-\mathrm{Zn} 1-\mathrm{N} 21$ & $106.31(6)$ \\
\hline N11-Zn1-N18 & $102.43(14)$ & $\mathrm{N} 11-\mathrm{Zn} 1-\mathrm{N} 21$ & $105.23(10)$ \\
\hline Zn1-N11-C12 & $124.4(2)$ & $\mathrm{Zn} 1-\mathrm{N} 11-\mathrm{C} 12$ & $123.28(19)$ \\
\hline Zn1-N11-C16 & $115.4(2)$ & $\mathrm{Zn} 1-\mathrm{N} 11-\mathrm{C} 16$ & $117.8(2)$ \\
\hline Zn1-N18-H18a & $112(3)$ & $\mathrm{Zn} 1-\mathrm{N} 21-\mathrm{C} 22$ & $129.86(19)$ \\
\hline Zn1-N18-H18b & $104(3)$ & $\mathrm{Zn1-N21-C26}$ & $111.24(17)$ \\
\hline
\end{tabular}

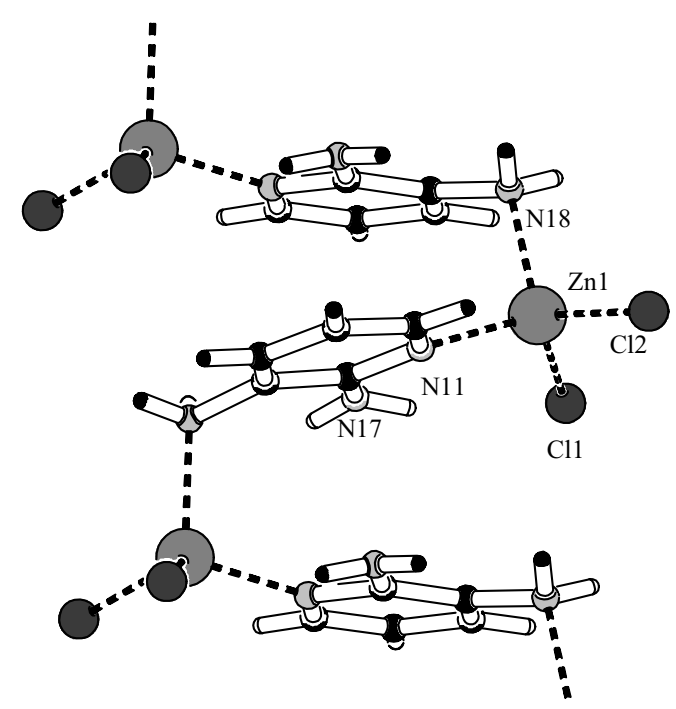

Fig. 1. Pluton [12] projection showing the one-dimensional $\left[\mathrm{Zn}(\mathrm{dap}) \mathrm{Cl}_{2}\right]_{n}$ zig-zag neutral chain of (1).

nitrogen atom. The two $\mathrm{Zn}-\mathrm{Cl}$ bond distances ( $\mathrm{Zn}$ $\mathrm{Cl} 1=2.2476(12) \quad \AA$ and $\mathrm{Zn}-\mathrm{Cl} 1=2.2264(12) \AA$ ) are slightly longer than those typically observed for dichlorobis(substituted pyridine)Zn(II) complexes [18], but they are comparable to those of $\mathrm{Zn}\left(2-\mathrm{NH}_{2} \text { py }\right)_{2} \mathrm{Cl}_{2}$ [8]. Both $\mathrm{Cl}$ ions accept two hydrogen bonds. The zinc to nitrogen bond distances are $\mathrm{Zn} 1-\mathrm{N} 11=2.046(3) \AA$ and $\mathrm{Zn} 1-\mathrm{N} 18=2.104(3) \AA$ for the pyridine and amino nitrogens, respectively. The first is not unusual and is similar to those reported for other $\mathrm{Zn}$ complexes [1922]. However, the second distance is longer than usually observed for similar compounds, as a result of the bridging coordination mode of the 2,3-diaminopyridine ligand. The coordination polyhedron of the zinc center is a distorted tetrahedron, with angles around the metal ion in the range $102.43(14)^{\circ}-112.78(4)^{\circ}$. Within the 
chain, the diaminopyridine rings are nearly parallel (the acute angle between the least-squares planes through the ring atoms is $13.31(16)^{\circ}$ ), but are displaced with respect to one another, resulting in a rather long distance between their centers $(4.556(2) \AA)$. Thus, any $\pi-\pi$ interaction between the rings must be relatively weak [23].

The most interesting feature of the crystal structure of $\mathbf{1}$ is the presence of multiple intra- and intermolecular hydrogen bonds (Fig. 2). The hydrogen bond parameters are given in Table 3. There is one intramolecular hydrogen bond of type $\mathrm{N}-\mathrm{H}$. . Cl between one chloride ion and the closest amino group of the dap ligand. The $\left[\mathrm{Zn}(\mathrm{dap}) \mathrm{Cl}_{2}\right] \mathrm{n}$ chains are linked together through hydrogen bonds of type $\mathrm{N}-\mathrm{H} \cdots \mathrm{Cl}$ involving chloride anions and amine hydrogen atoms of adjacent chains. The hydrogen bonds N17-H17B $\cdots \mathrm{Cl} 2[x-1,1 / 2-y$, $z-1 / 2]$ and N18-H18A $\cdots \mathrm{Cl} 2[1-x, 1-y, 1-z]$ link adjacent $\mathrm{Zn}$-ligand chains (which run in direction [0 10 l)

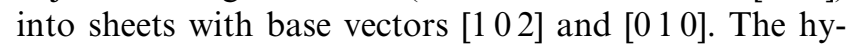
drogen bond $\mathrm{N} 18-\mathrm{H} 18 \mathrm{~B} \cdots \mathrm{Cl} 1[1-x, 1 / 2+y, 1 / 2-z]$

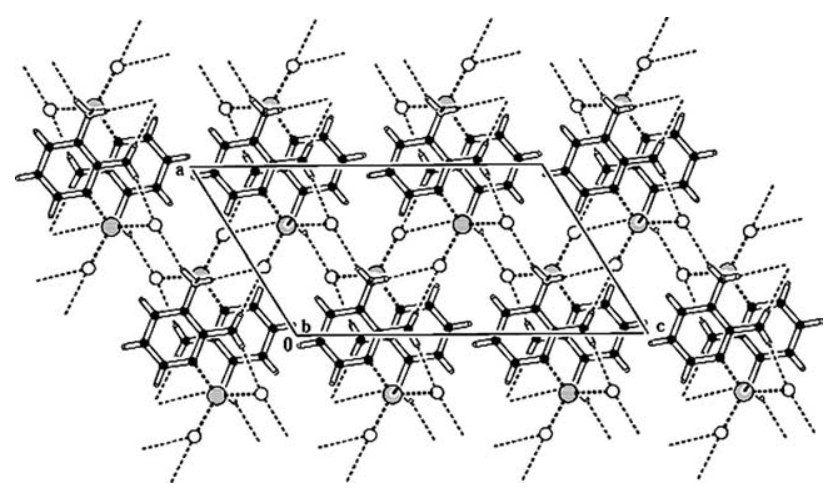

Fig. 2. The crystal packing of $\left[\mathrm{Zn}(\mathrm{dap}) \mathrm{Cl}_{2}\right](\mathbf{1})$, as viewed along the $b$ axis.

Table 3

Hydrogen bond parameters $\left(\AA^{\circ}\right.$ and $\left.{ }^{\circ}\right)$

\begin{tabular}{lllll}
\hline $\mathrm{D}-\mathrm{H} \cdots \mathrm{A}$ & $\mathrm{D}-\mathrm{H}$ & $\mathrm{H} \cdots \mathrm{A}$ & $\mathrm{D} \cdots \mathrm{A}$ & $\mathrm{D}-\mathrm{H} \cdots \mathrm{A}$ \\
\hline$\left[Z n(\right.$ dap $\left.) C l_{2}\right]$ & & & & \\
$\mathrm{N} 17-\mathrm{H} 17 \mathrm{~A} \cdots \mathrm{Cl} 1$ & $0.84(6)$ & $2.43(6)$ & $3.252(4)$ & $167(3)$ \\
$\mathrm{N} 17-\mathrm{H} 17 \mathrm{~B} \cdots \mathrm{Cl} 2^{\mathrm{i}}$ & $0.84(5)$ & $2.55(5)$ & $3.341(3)$ & $159(4)$ \\
$\mathrm{N} 18-\mathrm{H} 18 \mathrm{~A} \cdots \mathrm{Cl} 2^{\mathrm{ii}}$ & $0.82(4)$ & $2.59(4)$ & $3.347(3)$ & $155(4)$ \\
$\mathrm{N} 18-\mathrm{H} 18 \mathrm{~B} \cdots \mathrm{Cl} 1^{\mathrm{iii}}$ & $0.86(6)$ & $2.44(6)$ & $3.267(4)$ & $160(4)$ \\
& & & & \\
{$\left[Z n(\text { dap })_{2} C l_{2}\right]$} & & & & \\
$\mathrm{N} 17-\mathrm{H} 17 \mathrm{~A} \cdots \mathrm{Cl} 1$ & $0.856(17)$ & $2.470(17)$ & $3.289(3)$ & $160.6(18)$ \\
$\mathrm{N} 17-\mathrm{H} 17 \mathrm{~B} \cdots \mathrm{N} 18$ & $0.852(15)$ & $2.42(2)$ & $2.759(4)$ & $104.7(13)$ \\
$\mathrm{N} 17-$ & $0.852(15)$ & $2.231(13)$ & $3.061(3)$ & $164.7(19)$ \\
$\mathrm{H} 17 \mathrm{~B} \cdots \mathrm{N} 28^{\mathrm{iii}}$ & & & & \\
$\mathrm{N} 18-\mathrm{H} 18 \mathrm{~A} \cdots \mathrm{Cl} 2^{\mathrm{iv}}$ & $0.849(16)$ & $2.630(16)$ & $3.476(3)$ & $174.6(18)$ \\
$\mathrm{N} 27-\mathrm{H} 27 \mathrm{~A} \cdots \mathrm{Cl} 1$ & $0.844(15)$ & $2.480 .(13)$ & $3.295(2)$ & $162(2)$ \\
$\mathrm{N} 27-\mathrm{H} 27 \mathrm{~B} \cdots \mathrm{N} 28$ & $0.84(2)$ & $2.46(2)$ & $2.769(3)$ & $102.8(19)$ \\
$\mathrm{N} 27-\mathrm{H} 27 \mathrm{~B} \cdots \mathrm{N} 18^{\mathrm{v}}$ & $0.84(2)$ & $2.34(2)$ & $3.173(3)$ & $170(2)$ \\
\hline
\end{tabular}

Symmetry codes: (i) $-1+x, 1 / 2-y,-1 / 2+z$; (ii) $1-x, 1-y$, $1-z$; (iii) $1-x, 1 / 2+y, 1 / 2-z$; (iv) $1+x, 1 / 2-y, 1 / 2+z$; (v) $1-x$, $-1 / 2+y, 1 / 2-z$. links adjacent chains into sheets with base vectors [ $\left[\begin{array}{lll}1 & 0 & 0\end{array}\right]$ and $\left[\begin{array}{lll}0 & 1 & 0\end{array}\right]$. Combination of all these hydrogen bonds results in a three-dimensional network.

A Pluton projection of the mononuclear unit of $\mathbf{2}$ is depicted in Fig. 3. The pseudo-tetrahedral zinc(II) coordination polyhedron consists of two monodentate dap ligands and two chloride ions, with the angles around the metal center falling in the range $105.22(8)^{\circ}-$ $112.42(6)^{\circ}$ (Table 2). The two $\mathrm{Zn}-\mathrm{Cl}$ bond distances are similar $(\mathrm{Zn}-\mathrm{Cl} 1=2.2478(7) \AA$ and $\mathrm{Zn}-\mathrm{Cl} 2=2.2475(7)$ $\AA)$ and are within the range of $\mathrm{Zn}-\mathrm{Cl}$ bond distances observed for similar compounds [8]. The $\mathrm{Zn}-\mathrm{N}$ bond distances are slightly different $(\mathrm{Zn}-\mathrm{N} 11=2.038(2) \AA$ and $\mathrm{Zn}-\mathrm{N} 21=2.050(2) \AA)$ and both comparable with those in other zinc complexes containing pyridine-based ligands [19-22].

The mononuclear units of $\mathbf{2}$ are further stabilized by the presence of weak intramolecular hydrogen bonds established between the amino groups of the same dap

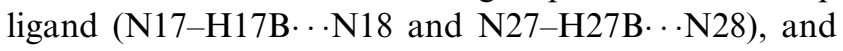
between the ortho amino group of each dap ligand and one of the chloride ions (N17-H17A ...Cl1 and N27H27A ...Cl1) (Fig. 4 and Table 3). The mononuclear

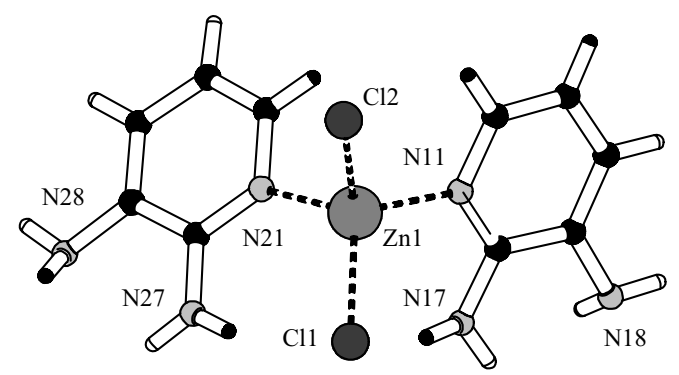

Fig. 3. Pluton[12] projection of the molecular structure of $\left[\mathrm{Zn}(\operatorname{dap})_{2} \mathrm{Cl}_{2}\right](\mathbf{2})$.

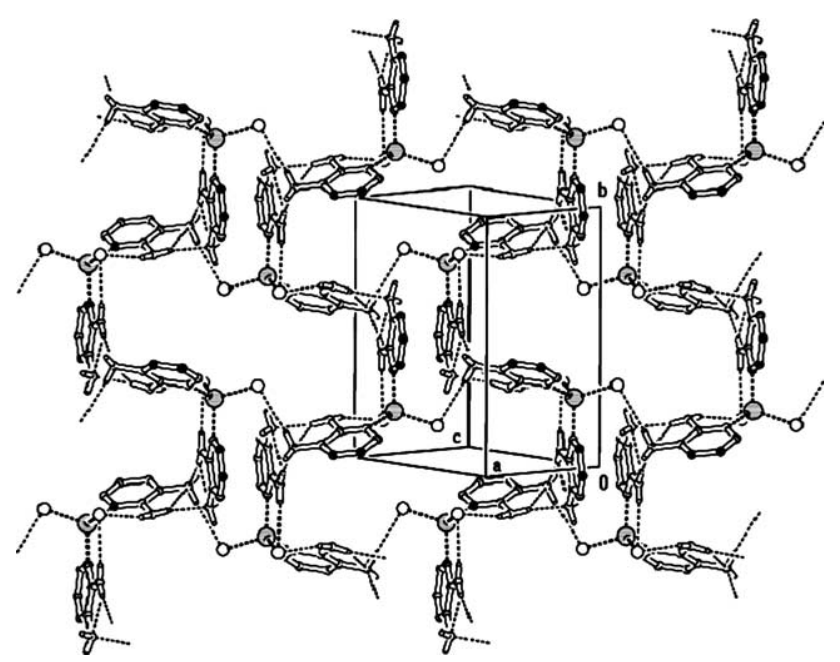

Fig. 4. The two-dimensional hydrogen-bonded layer of $\left[\mathrm{Zn}(\mathrm{dap})_{2} \mathrm{Cl}_{2}\right]_{n}$ (2). Hydrogen atoms bonded to carbon have been omitted for clarity. 
$\left[\mathrm{Zn}(\mathrm{dap})_{2} \mathrm{Cl}_{2}\right]$ units are linked into two-dimensional sheets parallel to the $(10-2)$ lattice planes through $\mathrm{N}_{-}$ $\mathrm{H} \cdots \mathrm{N}$ hydrogen bonds involving the amino groups of adjacent molecules and $\mathrm{N}-\mathrm{H} \cdots \mathrm{Cl}$ hydrogen bonds involving the second chloride ion and one amino group of a neighboring molecule (Fig. 4 and Table 3). At the interfaces between the hydrogen-bonded layers, the diaminopyridine rings are assembled in a facial arrangement, allowing $\pi-\pi$ stacking interactions with Cg. . Cg distances of 3.4860(15) $\AA$ and 3.8868(19) $\AA$ [22] ( $C_{\mathrm{g}}$ is the geometrical center of a ring), which connect the layers into a three-dimensional network.

\section{Supplementary material}

Crystallographic data (excluding structure factors) have been deposited with the Cambridge Crystallographic Data Centre as supplementary publication No. CCDC-222186 and 222187. Copies of the data can be obtained free of charge on application to The Director, CCDC, 12 Union Road, Cambridge, CB2 1EZ, UK (fax: +44-1223-336-033; e-mail: deposit@ccdc.cam. ac.uk or $<$ http//www.ccdc.cam.ac.uk>).

\section{Acknowledgements}

This work was supported by a Training Network Grant from the EU in the 5th Framework programme (MEDICINOR; Grant No. HPMT-CT-2000-00192). This work was supported in part (ALS, AMM) by the Council for the Chemical Sciences of the Netherlands Organization for Scientific Research (CW-NWO). The authors are indebted to MCYT (Spain) for financial support (PPQ2000-0035-P4).

\section{References}

[1] A.J. Blake, N.R. Champness, P. Hubberstey, W.S. Li, M.A. Withersby, M. Schroder, Coord. Chem. Rev. 183 (1999) 117.

[2] D. Braga, F. Grepioni, Acc. Chem. Res. 33 (2000) 601.

[3] C. Janiak, Dalton Trans. (2003) 2781.

[4] B. Moulton, M.J. Zaworotko, Chem. Rev. 101 (2001) 1629.

[5] H.W. Roesky, M. Andruh, Coord. Chem. Rev. 236 (2003) 91.

[6] O.R. Evans, W.B. Lin, Acc. Chem. Res. 35 (2002) 511.

[7] O.R. Evans, W.B. Lin, Chem. Mater. 13 (2001) 2705.

[8] J.G. Qin, N.B. Su, C.Y. Dai, C.L. Yang, D.Y. Liu, M.W. Day, B.C. Wu, C.T. Chen, Polyhedron 18 (1999) 3461.

[9] Z. Peng, L. Yu, J. Am. Chem. Soc. 118 (1996) 1623.

[10] D.W. Bruce, A. Thornton, Mol. Cryst. Liquid Cryst. 189 (1993) 253.

[11] L.-T. Cheng, W. Tam, D.F. Eaton, Organometallics 9 (1990) 2856.

[12] A.L. Spek, PLATON, a Multipurpose Crystallographic Tool, Utrecht University, Utrecht, The Netherlands, 2000.

[13] P.T. Beurskens, G. Admiraal, G. Beurskens, W.P. Bosman, S. Garcia-Granda, R.O. Gould, J.M.M. Smits, C. Smykalla, The DIRDIF Program System, Technical Report of the Crystallography Laboratory, University of Nijmegen, Nijmegen, The Netherlands, 1992.

[14] G.M. Sheldrick, ShelXl97. Program for Crystal Structure Solution, University of Göttingen, Göttingen, Germany, 1997.

[15] G.M. Sheldrick, Shelxl97. Program for Crystal Structure Refinement, University of Göttingen, Göttingen, Germany, 1997.

[16] S. Haghighi, C.A. McAuliffe, Inorg. Chim. Acta 43 (1980) 113.

[17] L. Fidalgo, M.A. Garralda, R. Hernandez, L. Ibarlucea, J. Organomet. Chem. 447 (1993) 299.

[18] W.L. Steffen, G.J. Palenik, Inorg. Chim. Acta 16 (1977) 1119.

[19] L. Boge, U. Pretzmann, N. Jensen, C.E. Sotofte, J. Olsen, Inorg. Chim. Acta 40 (2001) 2323.

[20] M. Ray, B.S. Hammes, G.P.A. Yap, A.L. Rheingold, A.S. Borovik, Inorg. Chim. Acta 37 (1998) 1527.

[21] P. Ghosh, P.K. Bharadwaj, J. Chem. Soc., Dalton Trans. (1997) 2673.

[22] J. Romero, J.A. Garcia-Vazquez, M.L. Duran, A. Castineiras, A. Sousa, A.D. Garnovskii, D.A. Garnovskii, Acta Chem. Scand. 51 (1997) 672.

[23] C. Janiak, J. Chem. Soc., Dalton Trans. (2000) 3885. 